Louisiana State University

LSU Digital Commons

$1-1-2014$

\title{
The influence of the complex topography and dynamic history of the montane Neotropics on the evolutionary differentiation of a cloud forest bird (Premnoplex brunnescens, Furnariidae)
}

\author{
Eugenio Valderrama \\ Universidad de Los Andes, Colombia \\ Jorge L. Pérez-Emán \\ Universidad Central de Venezuela, Facultad de Ciencias \\ Robb T. Brumfield \\ Louisiana State University \\ Andrés M. Cuervo \\ Louisiana State University \\ Carlos Daniel Cadena \\ Universidad de Los Andes, Colombia
}

Follow this and additional works at: https://digitalcommons.Isu.edu/biosci_pubs

\section{Recommended Citation}

Valderrama, E., Pérez-Emán, J., Brumfield, R., Cuervo, A., \& Cadena, C. (2014). The influence of the complex topography and dynamic history of the montane Neotropics on the evolutionary differentiation of a cloud forest bird (Premnoplex brunnescens, Furnariidae). Journal of Biogeography, 41 (8), 1533-1546. https://doi.org/10.1111/jbi.12317

This Article is brought to you for free and open access by the Department of Biological Sciences at LSU Digital Commons. It has been accepted for inclusion in Faculty Publications by an authorized administrator of LSU Digital Commons. For more information, please contact ir@lsu.edu. 


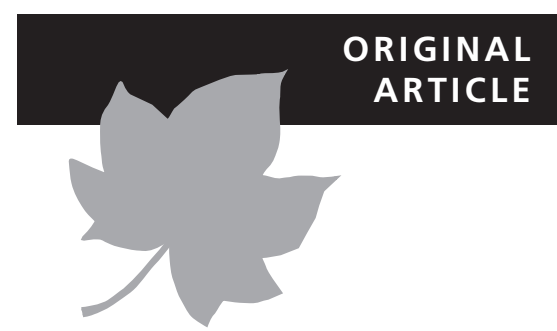

\title{
The influence of the complex topography and dynamic history of the montane Neotropics on the evolutionary differentiation of a cloud forest bird (Premnoplex brunnescens, Furnariidae)
}

\author{
Eugenio Valderrama ${ }^{1,2 *}$, Jorge L. Pérez-Emán ${ }^{3,4}$, Robb T. Brumfield ${ }^{5}$,
} Andrés M. Cuervo ${ }^{5}$ and Carlos Daniel Cadena ${ }^{1}$

${ }^{1}$ Departamento de Ciencias Biológicas,

Laboratorio de Biología Evolutiva de Vertebrados, Universidad de los Andes, Bogotá, Colombia, ${ }^{2}$ Tropical Diversity Section, Royal Botanic Garden Edinburgh, Edinburgh EH3 $5 L R, U K,{ }^{3}$ Instituto de Zoología y Ecología Tropical, Facultad de Ciencias, Universidad Central de Venezuela, Caracas 1041-A, Venezuela, ${ }^{4}$ Colección Ornitológica Phelps, Caracas 1010-A, Venezuela, ${ }^{5}$ Department of Biological Sciences and Museum of Natural Science, Louisiana State University, Baton Rouge, LA 70803, USA

${ }^{*}$ Correspondence: Eugenio Valderrama Escallón, Royal Botanic Garden Edinburgh, 20A Inverleith Row, Edinburgh EH3 5LR, UK. E-mail: e.valderrama.e@gmail.com

\begin{abstract}
Aim To examine the effect of geographical barriers and habitat dynamics related to climatic oscillations on the phylogeography of a widespread passerine of Neotropical cloud forests, the spotted barbtail (Premnoplex brunnescens).
\end{abstract}

Location Neotropical humid forests of montane areas in lower Central America and South America.

Methods We sequenced two mitochondrial genes and one nuclear intron from specimens collected across the distribution of P. brunnescens. Phylogenetic relationships were inferred using Bayesian and maximum-likelihood methods. Groups with maximum differentiation were estimated with spatial analysis of molecular variance (SAMOVA). We estimated timing of differentiation and relationships among groups with a species-tree approach and historical demography with extended Bayesian skyline plots.

Results Six highly differentiated clades of $P$. brunnescens are distributed in lower Central America, Sierra Nevada de Santa Marta, northern Venezuelan mountains, the Northern Andes, central Peru, and southern Peru and Bolivia. Within the Northern Andes clade, six phylogroups were identified associated with different slopes and isolated cordilleras. Most clades occupy opposite sides of low-lying valleys and ridgelines, but little differentiation was observed across several putative barriers. Population divergence occurred in the late Miocene and Pliocene, perhaps in association with Andean uplift. Historical fluctuations in population sizes suggest that populations tracked the spatial dynamics of montane forests associated with glacial cycles.

Main conclusions Extensive genetic differentiation in mitochondrial and nuclear DNA exists among populations of P. brunnescens. Such marked divergence was probably promoted by the rugged topography and dynamic ecological history of the Neotropical mountains. Our study sheds light on mechanisms promoting population differentiation in the montane Neotropics.

\section{Keywords}

Andes, genetic differentiation, geographical barriers, historical demography, Neotropical montane forest, orogeny, phylogeography, Pleistocene, spotted barbtail.

\section{INTRODUCTION}

Populations of montane-forest species of the Neotropics are separated by physical and ecological barriers, including lowlying valleys and high-elevation ridgelines. These barriers are

(c) 2014 John Wiley \& Sons Ltd likely to prevent gene flow, promoting population differentiation. For example, species distributions and phenotypic and genetic variation indicate that arid zones such as those associated with the Marañón Valley are barriers for cloud forest organisms (Chapman, 1921; Vuilleumier, 1969; Gentry, 1982; 
Parker et al., 1985; Weir, 2009). Likewise, the Magdalena Valley separates populations from the Cordillera Central and Cordillera Oriental of Colombia in some species (Cadena et al., 2007; Gutiérrez-Pinto et al., 2012). High-elevation habitats above the tree line could also curtail gene flow by dividing forests on separate slopes, causing genetic differentiation across ridges (Guarnizo et al., 2009; Parra et al., 2009).

Environmental conditions at physical and ecological barriers have been dynamic, such that their permeability to gene flow has probably changed over time (Hooghiemstra \& van der Hammen, 2004; Cárdenas et al., 2011). Accordingly, population differentiation of cloud forest birds across valleys and ridgelines was probably modulated by elevational shifts of habitats (Vuilleumier, 1969). The role of glacial cycles in promoting population genetic differentiation and species diversification is still debated (Jansson \& Dynesius, 2002), especially in Neotropical montane forests (Weir, 2006), partly because of inconclusive palaeoecological evidence (Colinvaux et al., 2000; Hooghiemstra \& van der Hammen, 2004). Two models differing in the humidity associated with cool conditions have been proposed to describe the influence that Pleistocene glacial cycles had on Neotropical montane cloud forests (reviewed by Ramírez-Barahona \& Eguiarte, 2013). The dry refugia model poses that cloud forests were displaced downslope and compressed into refugia during cool and dry periods. If this were correct, then species inhabiting such forests should have experienced demographic expansion and re-colonization of their former ranges under humid and warmer conditions. Furthermore, population fragmentation would result in loss of genetic diversity and marked genetic differentiation among populations. In contrast, the moist forest model poses that humidity did not change in glacial periods, but that cool conditions promoted downslope displacement of forests without compression, with upslope displacement and fragmentation during warm interglacials. This model predicts range expansion and greater population connectivity across low elevations during glacial periods, but no demographic expansion during interglacials, leading to diffuse genetic structuring of populations, genetic diversity associated with spatial heterogeneity, and little concordance across co-distributed species (Ramírez-Barahona \& Eguiarte, 2013). Demographic changes related to glacial cycles have been documented for organisms in the temperate zone (Hewitt, 2000; Shapiro et al., 2004; Shepard \& Burbrink, 2009) and in the Afromontane region (Bowie et al., 2006), and some phylogeographical studies suggest that population expansions/contractions have occurred in Neotropical montane taxa (Koscinski et al., 2008; Mata et al., 2009; Pérez-Emán et al., 2010a; Marin et al., 2013). However, the episodes of population expansion and contraction expected under different models of Pleistocene climate have not been tested explicitly using coalescent-based approaches in Neotropical montane organisms.

Pre-Pleistocene events, such as the uplift of the Andes and the accompanying changes of the landscape may also have affected evolutionary diversification in this region. Neotropi- cal mountains uplifted asynchronously: whereas the Central Andes uplifted as a result of tectonic processes during the Palaeogene [c. 65-34 million years ago (Ma)], the major uplift of the Northern Andes started in the late Oligocene to early Miocene (c. $23 \mathrm{Ma}$ ). Mountain building in the Northern Andes peaked during the late Miocene and early Pliocene (c. 10-4 Ma), and continued throughout the Pliocene in eastern Colombia (Gregory-Wodzicki, 2000; Hoorn et al., 2010; Mora et al., 2010). Some studies have revealed divergence events seemingly related to Andean uplift (Cadena et al., 2007; Särkinen et al., 2007; Antonelli et al., 2009; Guarnizo et al., 2009; Quintero et al., 2013), while others show that differentiation closely followed Andean orogeny (Picard et al., 2007; Ribas et al., 2007; Chaves et al., 2011). Data for Neotropical montane birds suggest a wide span of population divergence dates; some divergence events might be related to pre-Pleistocene processes and others to Pleistocene dynamics (Weir, 2009).

In this study we examined the role of barriers related to montane topography and of climatic oscillations on population-level differentiation in the Neotropical highlands based on a phylogeographical analysis of the spotted barbtail (Premnoplex brunnescens) (Aves, Furnariidae). This suboscine passerine bird inhabits the understorey of humid montane forests (c. 900$2600 \mathrm{~m}$ ) in lower Central America, the Andes, and isolated mountain ranges from Venezuela to Bolivia (Remsen, 2003; Greeney, 2008). Premnoplex brunnescens forms a distinctive lineage (originated c. $19 \mathrm{Ma}$; Derryberry et al., 2011) with its sister species Premnoplex tatei (white-throated barbtail), which occurs allopatrically in north-eastern Venezuela (Pérez-Emán et al., 2010b). Its close association with forest understorey, its occurrence along the Andes and other mountain ranges bisected by various lowlands, valleys and ridgelines, and its existence as an independent lineage since the late Miocene (c. 8 Ma; Derryberry et al., 2011) make P. brunnescens a good candidate with which to examine processes involved in evolutionary differentiation in the Neotropical highlands. We examined phylogenetic relationships among geographically isolated populations of $P$. brunnescens using a comprehensive sample of individuals and considering both mitochondrial and nuclear DNA data, and assessed the role of geographical barriers in shaping patterns of population genetic structure. We also estimated the timing of divergence events among lineages and related such estimates to geological and climatic history. Finally, we tested for genetic signatures of demographic expansions and contractions potentially associated with Pleistocene glacial cycles.

\section{MATERIALS AND METHODS}

\section{Sampling}

We obtained 107 tissue samples of $P$. brunnescens from most of its known distribution (a total of 59 localities, Fig. 1) and representing its five described subspecies (Remsen, 2003). We also obtained sequences from six specimens of $P$. tatei, 
Figure 1 Geographical distribution of samples of Premnoplex brunnescens included in the analyses

demonstrating considerable coverage of the species' known distribution in Neotropical montane forest. Darker tones of grey indicate higher elevations. The shape and colour of symbols identify the subspecies and SAMOVA groups, respectively. Numbers correspond to the ID column in Appendix S1 and the arrows denote geographical features discussed in the text: (a) Cesar Depression, (b) Turbio-Yaracuy Depression, (c) Táchira Depression, (d) Central Panamanian lowlands, (e) maximum elevations of the Cordillera Oriental, (f) Magdalena Valley, (g) Cauca Valley, (h) Marañón Valley, (i) Huancabamba Depression, (j) Huallaga River, (k) Mantaro Valley, (l) Apurímac Valley, and (m) Urubamba Valley.

representing its two subspecies (Pérez-Emán et al., 2010b) (see Appendix S1 in Supporting Information); all the analyses treated $P$. tatei as part of the ingroup. Our outgroups were Margarornis squamiger, Margarornis rubiginosus and Pygarrhichas albogularis (sequences from Derryberry et al., 2011); Margarornis is sister to Premnoplex, and Pygarrhichas is a more distantly related furnariid (Derryberry et al., 2011).

\section{Laboratory procedures}

We extracted DNA using a DNeasy Tissue Kit (Qiagen, Valencia, CA, USA). When extractions were made from skin (toe) samples taken from specimens, we modified the manufacturer's protocol by using $30 \mu \mathrm{L}$ of Proteinase $\mathrm{K}(20 \mathrm{mg}$ / $\mathrm{mL}$ ) and incubated samples at $55{ }^{\circ} \mathrm{C}$ until most of the tissue was digested (up to 4 days). Additionally, we made two final elutions of $30 \mu \mathrm{L}$ each, with buffer at $70{ }^{\circ} \mathrm{C}$.

We sequenced two mitochondrial (mtDNA) genes: cytochrome $b$ [cyt $b, 1045$ base pairs (bp) for 106 individuals] and NADH dehydrogenase subunit 2 (ND2, 1041 bp for 104 $80^{\circ} 0^{\prime} \mathrm{O}^{\prime \prime} \mathrm{W} \quad 70^{\circ} 0^{\prime} \mathrm{O}^{\prime \prime} \mathrm{W}$

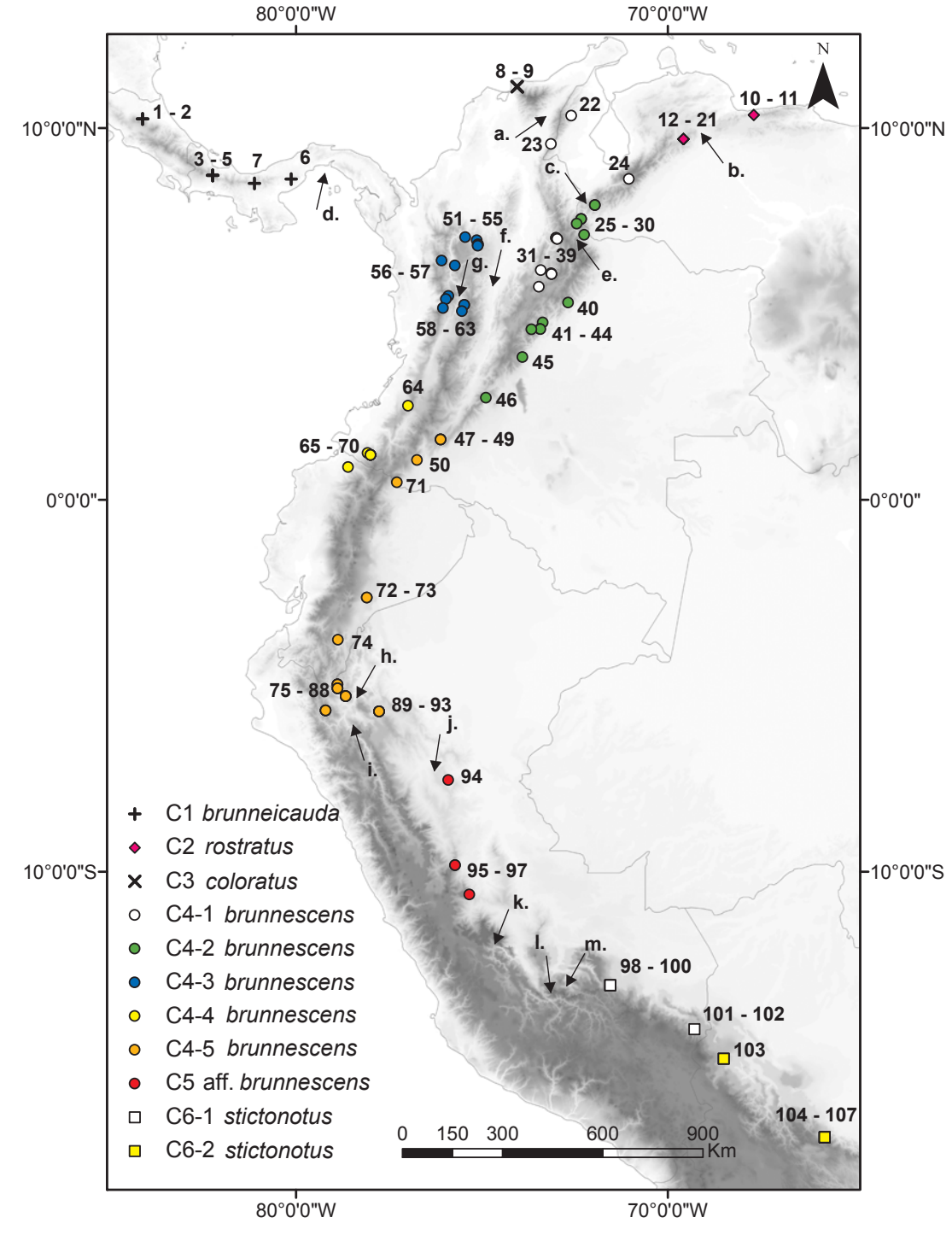

individuals). The nuclear intron 7 of the beta fibrinogen gene ( $\beta f i b 7,968 \mathrm{bp}$ ) was also sequenced for 70 individuals representing major groups recovered by analyses of mtDNA data and covering the species' geographical range. Whenever possible, we amplified each gene as a single fragment; alternatively, we amplified genes in two fragments (see primers in Appendix S2). Standard methods for DNA amplification and sequencing were employed (Cadena et al., 2007). Chromatograms were checked for stop codons in coding genes, and ambiguities in base calls and mismatches in overlapping sequences produced by different primer combinations were corrected in Geneious Pro 4.5.5 (Biomatters Development Team, 2008). In the nuclear region apparent heterozygosities were scarce and coded as ambiguities using IUPAC codes; insertions-deletions were treated as missing data.

\section{Phylogenetic analyses}

We aligned sequences using the MUSCLE algorithm (Edgar, 2004) in Geneious Pro 4.5.5 with default settings. The 
incongruence length difference test (Farris et al., 1995) implemented in PAUP ${ }^{*} 4.0 \mathrm{~b} 10$ (Swofford, 1998) did not reveal significant conflict in topologies recovered from different genes. Thus, we constructed three data sets: (1) 73 individuals (70 of $P$. brunnescens, 3 of $P$. tatei) for the $\beta f i b 7$ nuclear region, (2) 113 individuals for cyt $b$ and ND2 concatenated mitochondrial regions (107 of P. brunnescens, 6 of $P$. tatei), and (3) 69 individuals for combined $\beta f i b 7$, cyt $b$ and ND2 sequences (66 of P. brunnescens, 3 of P. tatei).

To assess relationships among haplotypes, we conducted phylogenetic analyses based on the three datasets using Bayesian inference in MrBayes 3.2.1 (Ronquist et al., 2012). Each analysis comprised four independent runs, each with one cold chain and three heated chains with incremental temperature of 0.125 ran for 20 million generations sampling every 1000 generations. We ran nine different analyses using different partitioning schemes (Appendix S2). The best-fit substitution model for each partition was selected using the Bayesian information criterion (BIC) in JModelTest 2.1.1 (Darriba et al., 2012). When models included more than one substitution type, we allowed MrBAYEs to explore different substitution schemes using reversible-jump sampling. To confirm convergence of independent runs and appropriate mixing we used statistics from MrBayes and inspected parameters in Tracer 1.5 (Rambaut \& Drummond, 2007). The first 5000 samples of each run (25\%) were discarded as burn-in. Partitioning schemes were compared with Bayes factors using the harmonic mean of likelihood values (Lartillot \& Philippe, 2006). The selected partitioning scheme was: two separate partitions based on codon positions (first and second positions separate from third positions) for the mtDNA dataset, and the same scheme with an extra partition for the nuclear intron for the combined mtDNA and $\beta$ fib7 dataset (Appendix S2).

We also analysed data using maximum-likelihood in GARLI 2.0 (Zwickl, 2006) run from the CIPRES portal (Miller et al., 2010). Likelihood values of partitioning schemes were compared with the small-sample size corrected Akaike information criterion ( $\mathrm{AIC}_{\mathrm{c}}$; McGuire et al., 2007). Each analysis included 100 bootstrap replicates with two independent search replicates. The best-fit substitution model for each partition was selected using the $\mathrm{AIC}_{\mathrm{c}}$ in JModelTest. The same partitioning schemes as in the Bayesian analysis were selected (Appendix S2). Nodal support was summarized with the SumTrees package (Sukumaran \& Holder, 2010).

\section{Genetic structure}

We examined relationships among mtDNA haplotypes within well-supported clades using statistical-parsimony networks (Templeton et al., 1992) constructed in R (R Development Core Team, 2012) with the package PEGAs (Paradis, $2010)$. We calculated uncorrected pairwise $(p)$-distances in MEGA 5.0 (Tamura et al., 2011) to measure genetic differentiation within and among clades obtained in phylogenetic analyses.
We estimated the number of groups of samples maximizing genetic structure among them using a spatial analysis of molecular variance (SAMOVA; Dupanloup et al., 2002) based on the mtDNA dataset and the georeferences of sampling sites. We chose the minimum number of groups $(K)$ maximizing the fixation index $\left(F_{\mathrm{CT}}\right)$ by comparing independent runs each consisting of 100 annealing processes for values of $K$ between 2 and 20 .

\section{Species tree and timing of differentiation}

To estimate phylogenetic relationships among populations identified by the SAMOVA while considering intragroup polymorphism and incomplete lineage sorting, we implemented the ${ }^{*}$ BEAST species-tree approach (Heled \& Drummond, 2010) in BEAST 1.7.4 (Drummond et al., 2012). Based on the BIC, HKY $+\mathrm{I}+\Gamma$ and HKY were selected as the best-fit substitution models for the mtDNA and nuclear datasets, respectively. We used the cyt $b$ substitution rate of $2.08 \%$ (SD $0.62 \%$ ) divergence per million years (Weir \& Price, 2011) to obtain branch lengths in units of time. To allow time-calibration of trees using the ND2 data, we related model-corrected distances for cyt $b$ with distances obtained using the combined cyt $b$ and ND2 data using linear regression (Appendix S3). Because the slope of this regression was $1.1\left(r^{2}=0.98\right)$, we multiplied the 0.0104 cyt $b$ per-lineage rate (SD 0.0031$)$ by 1.1 and fixed the product $(0.0114$, SD 0.0034 ) as the mean rate for calibration (Weir \& Price, 2011). We fitted a relaxed molecular clock with lognormally distributed rate-variation to the mtDNA data. We ran four independent chains for 50 million generations sampling every 1000 steps and discarded the first 10,000 as burn-in. We combined results of separate runs and used Tracer 1.5 to check effective sample sizes (ESS) of parameter estimates and convergence and mixing of runs. Because mixing was poor and estimates of the I and $\Gamma$ substitution-model parameters were correlated, we repeated the analysis using $\mathrm{HKY}+\Gamma$ to model substitutions in the mtDNA dataset, which resulted in appropriate mixing. We used TreeAnnotator 1.7.4 to obtain the $95 \%$ highest posterior density of estimates of node ages and FigTree 1.4.0 (Drummond \& Rambaut, 2007) to examine trees. We used DensiTree (Bouckaert, 2010) to jointly visualize all topologies included in the posterior sample.

\section{Historical demography}

To assess whether populations have experienced changes in size as predicted by the hypothesis that glacial cycles led to contractions and expansions of montane forests, we estimated changes in effective population size over time. Analyses were based on the extended Bayesian skyline plot (EBSP) method implemented in BEAST 1.7.4, which uses coalescentbased models to estimate posterior probabilities of effective population size over time (Heled \& Drummond, 2008). Analyses focused on the groups identified by the SAMOVA 
with more than 10 individuals. All the analyses included the pooled mtDNA sequences; the nuclear region was also included in the analyses of groups with at least 10 individuals having $\beta f i b 7$ sequences. We found no evidence of selection or recombination (DNASP 5 was used to apply Fu and Li's tests, the four-gamete test and the ZZ test statistic; Librado \& Rozas, 2009). Substitution models for each partition and a molecular clock were fitted as in the ${ }^{\star}$ BEAST analysis. We estimated population sizes under the 'coalescent: constant size' tree prior for each group independently and then used resulting values as the 'demographic.populationMean' prior starting value in EBSP runs (Heled, 2010). Each run consisted of $1 \times 10^{8}$ generations with sampling every 1000 steps of which 10,000 were discarded as burn-in. Operators were modified to enhance mixing (Heled, 2010). Because ESS in analyses involving samples from the Colombian Cordillera Central and Cordillera Occidental were low using this search strategy, we combined data from four different runs of $6 \times 10^{7}$ generations sampling every 1000 steps and discarding 6000 as burn-in. Skyline plots were constructed in R.

\section{RESULTS}

Genetic variation within P. brunnescens was substantial. We observed 52 unique $\beta f i b 7$ sequences among the 70 individuals sampled (40 variable characters, 21 of which were parsimony informative), and 94 unique sequences in the concatenated mitochondrial (cyt $b$ and ND2) dataset including 107 individuals (487 variable characters, 436 of which were parsimony informative). In the concatenated dataset including nuclear and mitochondrial data (499 variable characters, 453 parsimony informative), sequences of each of the 66 individuals were unique.

\section{Phylogenetic analyses}

Bayesian analyses using all datasets showed that $P$. brunnescens and $P$. tatei are reciprocally monophyletic sister taxa in all the topologies in posterior distributions. Analyses with mtDNA alone and combined with $\beta$ fib7 revealed six clades within P. brunnescens located in: (C1) Central America, (C2) Venezuelan northern mountains (Coastal Cordillera and north-easternmost Mérida Cordillera); (C3) Sierra Nevada de Santa Marta; (C4) Northern Andes from Venezuela to northern Peru; (C5) central Peru; and (C6) southern Peru and Bolivia (Fig. 2). The nuclear region $\beta f i b 7$ alone recovered C2, $\mathrm{C} 3$ and $\mathrm{C} 4$ (the latter with low posterior probability), but not C1, C5 and C6 (Fig. 2, Appendix S3).

Clades largely corresponded to subspecies designations, except for the central Peru clade (C5), which supposedly belongs to subspecies $P$. b. brunnescens but was divergent from populations referable to this taxon from the Northern Andes group (Fig. 1). Relationships among the six clades recovered by mtDNA were not clearly resolved, with the exception of the sister relationship between C5 and C6, supported by high posterior probabilities with $\beta f i b 7$ data alone and combined with the mtDNA datasets (0.97 and 1.00, respectively), and by a low probability (0.74) with the mtDNA dataset (Fig. 2).

The clade from the Northern Andes (C4) consisted of several phylogroups (some of which not strongly supported), including populations from: (C4-1) the eastern slope of the Cordillera Oriental of Colombia and the Venezuelan Andes; (C4-2) the western slope of the Colombian Cordillera Oriental, Serranía de Perijá and a sample from the Venezuelan Andes; (C4-3) the Colombian Cordillera Central and Cordillera Occidental; (C4-4) the south-western extreme of Colombia and north-western Ecuador; (C4-5) northern Peru, eastern Ecuador, south-eastern Colombia, and one individual from north-western Colombia (sample 53, Fig. 1); and (C4-6) areas immediately south of the Marañon Valley (Fig. 2). Within C6, samples from southern Peru (C6-1) and Bolivia (C6-2) appeared in separate phylogroups, but our sampling did not allow a detailed description of spatial patterns of genetic variation.

Maximum-likelihood analyses recovered the same clades and phylogroups with similar support values as in Bayesian analyses. For bootstrap values for the topology in Fig. 2, see Appendix S3.

\section{Genetic structure}

Uncorrected $p$-distances between $P$. tatei and $P$. brunnescens were $9.2-10.7 \%$ in mtDNA and $1.1-1.4 \%$ in $\beta f i b 7$ (Appendix S2). Distances between the six major clades of P. brunnescens were $7.0-8.9 \%$ in mtDNA and $0.2-0.8 \%$ in $\beta f i b 7$. Within phylogroups from the Northern Andes genetic differentiation was moderate: $0.6-1.7 \%$ in mtDNA and $<0.1-0.2 \%$ in $\beta f i b 7$. Even clades with broad geographical distributions (e.g. C4 from the Venezuelan Andes to northern Peru) showed relatively little genetic differentiation (mean 1.0\% in mtDNA and $0.1 \%$ in $\beta f i b 7$, Appendix S2) despite extending across several putative barriers. No haplotypes were shared among regions corresponding to phylogroups of the Northern Andes (C4), and the relationships between haplotypes were concordant with those recovered by the Bayesian and maximumlikelihood phylogenetic analyses (Fig. 3).

The minimum number of groups maximizing $F_{\mathrm{CT}}$ was identified by SAMOVA as 11 (Appendix S3). The 11 groups identified coincided with the six clades discussed above, but the Northern Andes samples were further subdivided into five groups corresponding to the first five phylogroups described above with a few minor differences. First, individuals from the south proximities of the Maranón Valley (samples 89 and 93) clustered with the phylogroup from northern Peru, eastern Ecuador and south-eastern Colombia. Second, a sample from north-western Colombia (53) related to the latter phylogroup in phylogenetic analyses clustered with individuals from the Colombian Cordillera Central and Cordillera Occidental. Third, a sample from south-eastern Colombia (48) not included in any phylogroup clustered with samples from northern Peru, eastern Ecuador and 


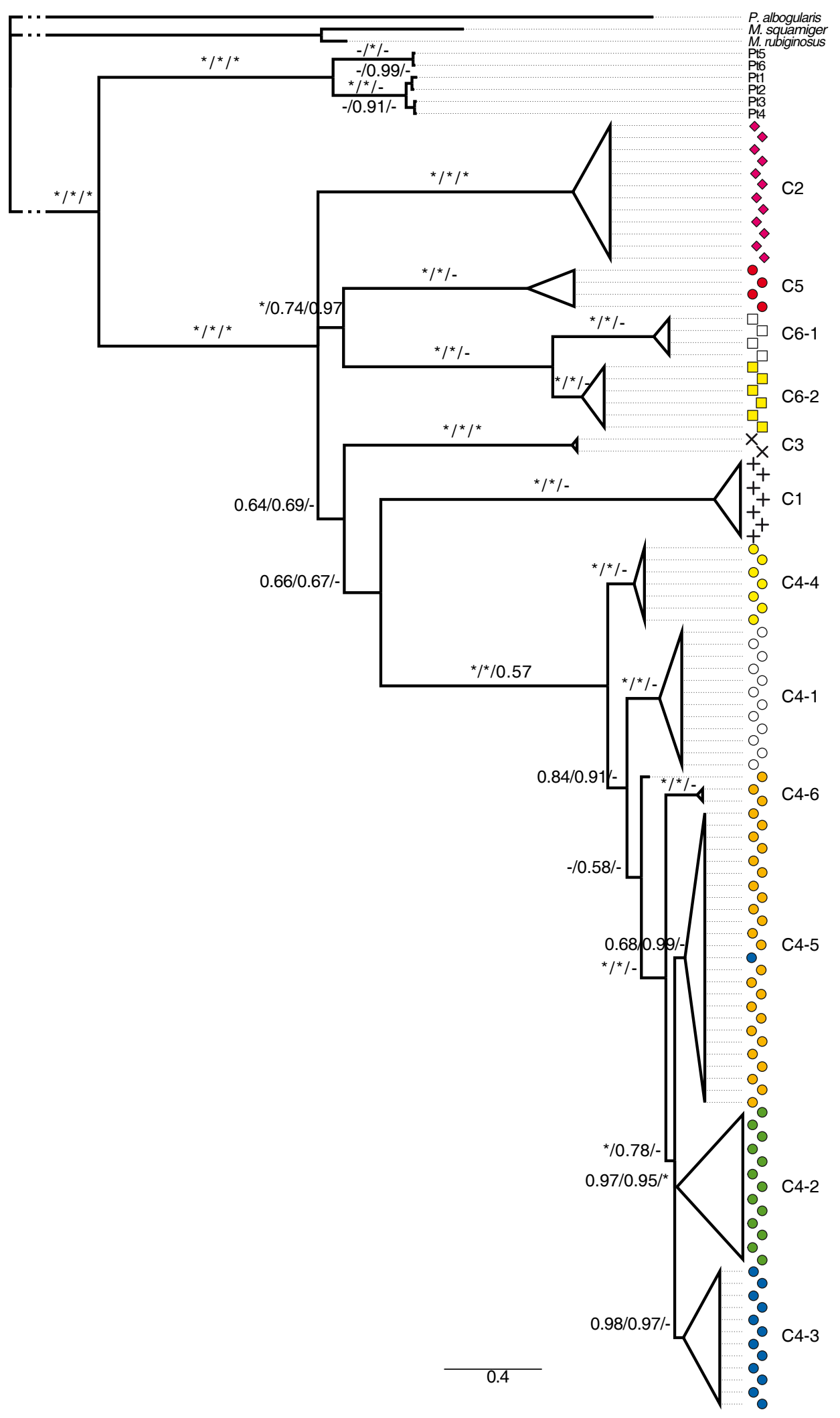

Figure 2 50\% majority-rule consensus tree from the Bayesian analysis of the mtDNA dataset showing phylogenetic relationships among samples of Premnoplex brunnescens, P. tatei and outgroups Margarornis squamiger, M. rubiginosus and Pygarrhichas albogularis. Posterior probability obtained for each node with the different datasets (mtDNA $+\beta f i b 7 / \mathrm{mtDNA} / \beta$ fib7) is shown with asterisks $\left({ }^{*}\right)$ denoting maximum posterior probability and dashes $(-)$ when the node was not recovered with the respective dataset. Clades are indicated as in the text, and shapes and colours of symbols are shown in Fig. 1. 
Phylogeography of the spotted barbtail

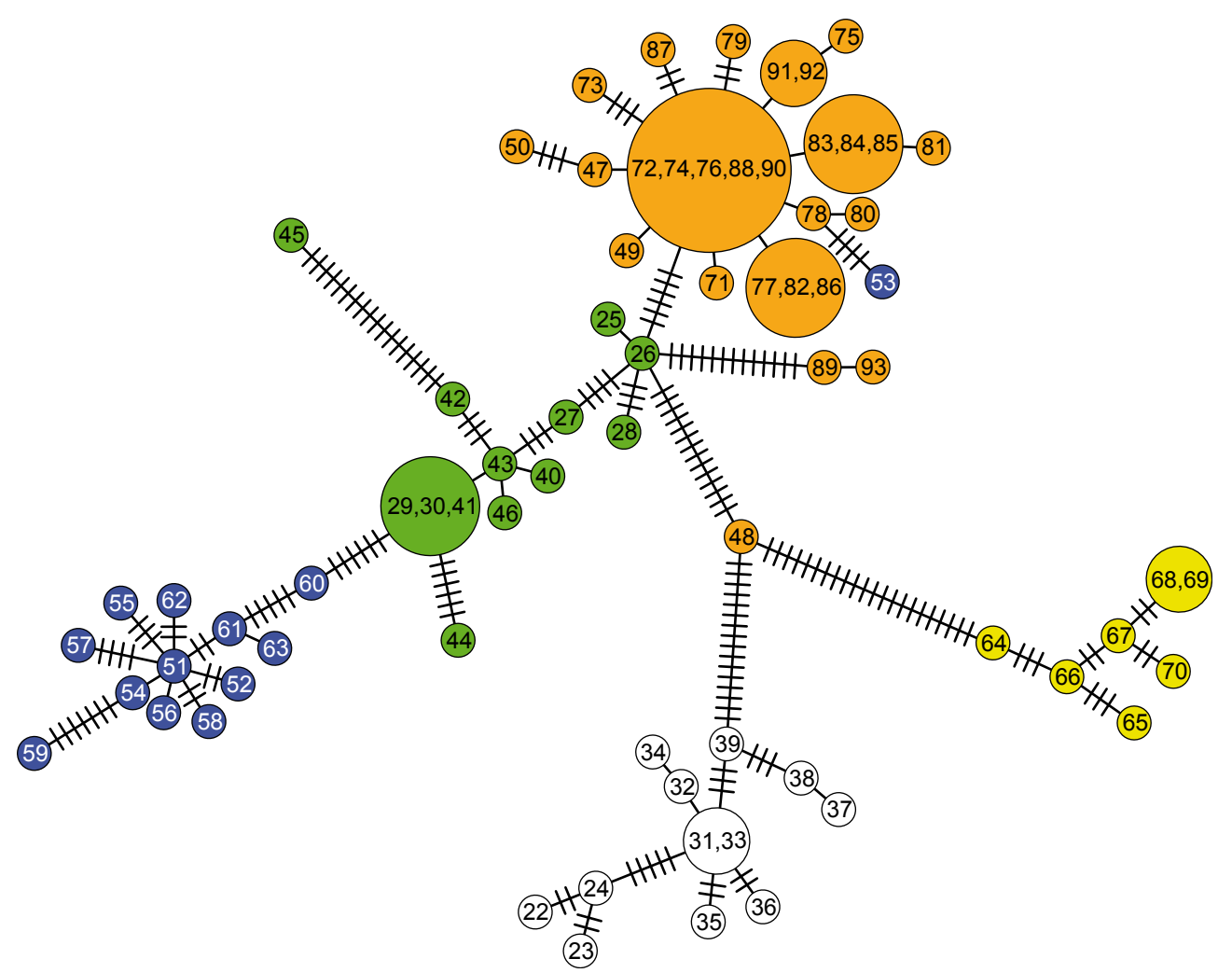

Figure 3 Network showing relationships among the Northern Andes haplotypes of Premnoplex brunnescens. Circle sizes are proportional to the number of individuals sampled with each haplotype and the number of changes is indicated with dashes along branches (when no dashes are shown, haplotypes are separated by a single mutational step). Colours identify locations within the Northern Andes as in Fig. 1.

south-eastern Colombia (Fig. 1). The samples from southern Peru and Bolivia are divided in the same phylogroups mentioned above.

\section{Species trees and timing of differentiation}

Our species-tree analysis confirmed that P. brunnescens and $P$. tatei are reciprocally monophyletic sister taxa, a result found in every topology in the posterior distribution (Fig. 4). Relationships among the six clades of P. brunnescens recovered based on mtDNA data are not clearly resolved in the species tree, with the exception of the clade including lineages from central Peru (C5) and southern Peru and Bolivia (C6). This analysis also splits a group containing the clades from the Venezuelan northern mountains (C2), central Peru (C5), and southern Peru and Bolivia (C6) from the other northern clades, but with poor support (posterior probability 0.43).

The time-calibrated species tree indicated that divergence between P. brunnescens and P. tatei occurred c. 7.6 Ma (95\% highest posterior density range, HPD: 4.1-11.2 Ma]. Divergence of major clades within P. brunnescens dated to between 5.3 and $3.2 \mathrm{Ma}$ (95\% HPD: 1.2-7.3 Ma), during the late Miocene and Pliocene (Fig. 4a). Divergences between phylogroups occurring in southern Peru and Bolivia and within the Northern Andes dated to the Pleistocene, between 0.9 and 0.2 Ma, respectively (95\% HPD: 0.1-1.5 Ma). Divergence between Central and South America was dated at 4.1 Ma (95\% HPD: 2.0-6.3 Ma).

\section{Historical demography}

Five of the 11 groups identified by SAMOVA had more than 10 individuals, allowing for demographic analyses: Venezuelan northern mountains $(\mathrm{C} 2 ; 11$ individuals with mtDNA and $\beta f i b 7$ data), the eastern slope of the Cordillera Oriental of Colombia and Venezuelan Andes (C4-2; 13 individuals, mtDNA), the western slope of the Colombian Cordillera Oriental, Serranía de Perijá and Venezuelan Andes (C4-1; 12 individuals, mtDNA), the Colombian Cordillera Central and Cordillera Occidental (C4-3; 13 individuals, mtDNA), and northern Peru, eastern Ecuador and south-eastern Colombia (C4-5; 20 individuals, mtDNA and $\beta f i b 7)$. Although the credible intervals in the ESBPs were wide and only in the case of the Colombian Cordillera Central and Cordillera Occidental was the 95\% HPD estimate of population change over time different from zero (Fig. 5d), genetic variation in four of the five groups analysed suggests demographic expansions over the last 200,000 years. In these groups, the distributions of the parameter describing changes in population 


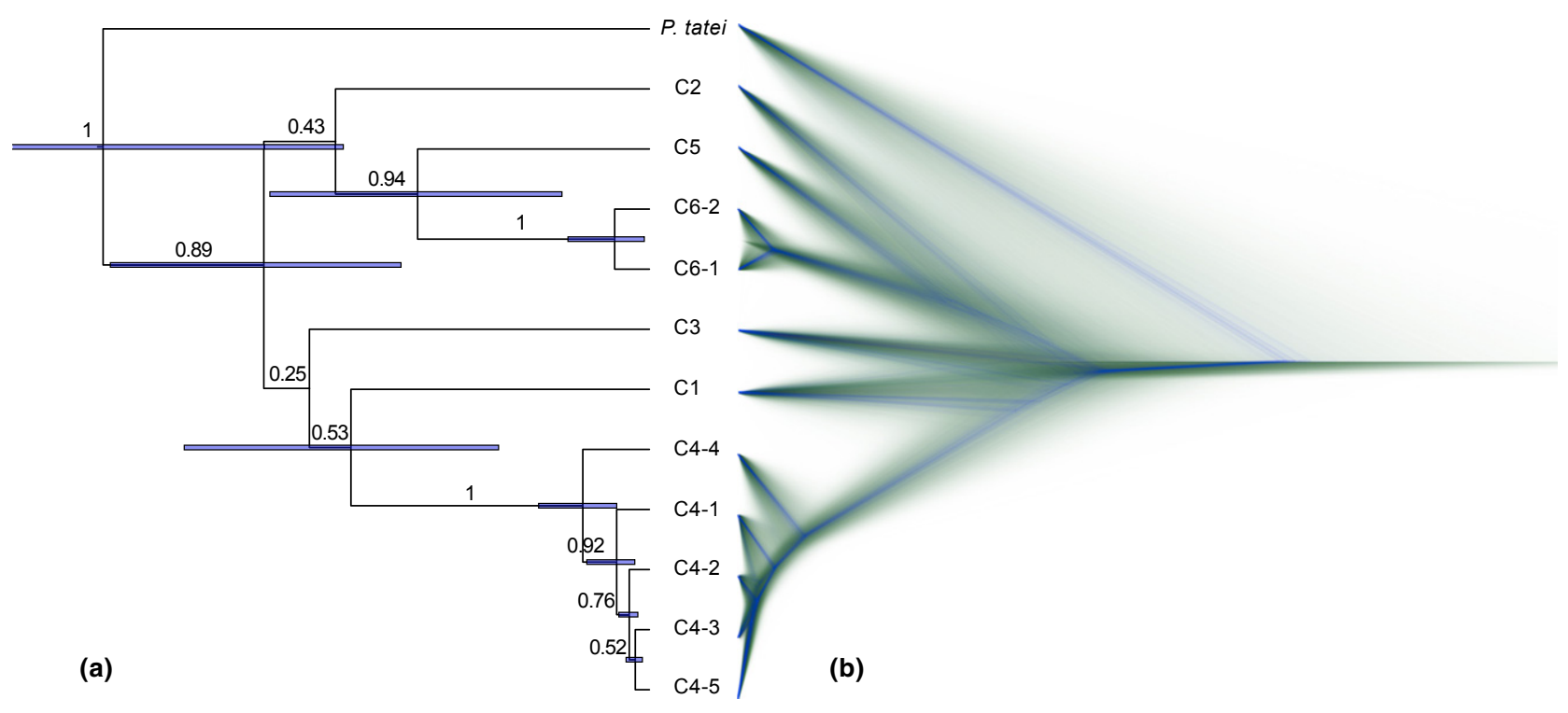

\begin{tabular}{lllllllll}
8.0 & 7.0 & 6.0 & 5.0 & 4.0 & 3.0 & 2.0 & 1.0 & 0.0 \\
\hline
\end{tabular}

Figure 4 (a) Maximum clade credibility tree of the ${ }^{\star}$ BEAST analysis showing relationships and divergence times (bars correspond to the 95\% highest posterior density range) among the groups of Premnoplex brunnescens defined by SAMOVA and P. tatei, with posterior probabilities shown above branches. (b) All the trees found in the posterior distribution of the analysis are shown in pale green. Each possible topology is shown in blue with branch lengths averaged among all trees showing that particular topology.

size are not centred on zero (all have a median of one; Fig. 5). In contrast, the population from the eastern slope of the Cordillera Oriental of Colombia and the Venezuelan Andes shows no signal of change (Fig. 5b).

\section{DISCUSSION}

Strong genetic differentiation among populations of $P$. brunnescens points to the importance of physical barriers and changes in the landscape occurring since the Miocene in shaping its evolutionary history. The timing of species and population differentiation suggests a span of dates including some potentially associated with mountain building in the Andes over the last 10 million years and some with events in the Pleistocene. This temporal framework, together with the inferred instability of population sizes presumably related to climatic fluctuations associated with glacial cycles in some regions, suggests that several geographical, orogenic and climatological phenomena are likely to be responsible for genetic differentiation among populations.

\section{Phylogenetics and population genetic structure}

Despite analysing > $3000 \mathrm{bp}$ from the mitochondrial and nuclear genomes, relationships among major clades of $P$. brunnescens were not clearly resolved, suggesting a burst of differentiation early on in the history of this group. Similar results in other clades (Pérez-Emán, 2005; Cadena et al., 2007; Chaves et al., 2011; Gutiérrez-Pinto et al., 2012) suggest that this may be a general pattern in the diversification of Neotropical montane birds.
The independent evolution of six major lineages in P. brunnescens has proceeded to the point that they are not only highly differentiated in mtDNA, but also nearly reciprocally monophyletic in a nuclear gene, despite the fourfold longer coalescence time of the latter (Moore, 1995). There is also agreement with phenotypic variation described in this taxon because subspecies taxonomy is congruent with patterns of genetic differentiation. The only exception is the population from central Peru, referred to $P . b$. brunnescens but forming a clade with populations referred to $P$. $b$. stictonotus of southern Peru and Bolivia. Genetic distances between major clades of $P$. brunnescens $(7.0-8.9 \%$ in mtDNA) are among the highest reported for within-species differentiation in Neotropical montane birds (Weir, 2009), are even greater than those between some furnariid congeneric species (García-Moreno et al., 1999; Sanín et al., 2009; Claramunt et al., 2013), and are similar to those among species in other Andean bird genera (García-Moreno \& Fjeldså, 2000). Therefore, under a variety of species concepts and criteria (de Queiroz, 2007), the major lineages we recovered could be considered separate species. Future studies should examine the phenotypic distinctiveness of the central Peru clade, and address whether genetic differentiation is concordant with patterns of variation in other traits (e.g. vocalizations) to fully assess whether $P$. brunnescens comprises multiple, reproductively isolated species.

The strong population genetic differentiation in P. brunnescens is probably related to its ecology: understorey birds often have limited dispersal abilities (Moore et al., 2008), and could be strongly affected by physiographical and ecological barriers or isolation by distance (Burney \& Brumfield, 
Figure 5 Changes in population sizes in the last 200,000 years obtained in the extended Bayesian skyline plot (EBSP) analyses for the groups of Premnoplex brunnescens from (a) Venezuelan northern mountains; (b) the eastern slope of the Cordillera Oriental of Colombia and Venezuelan Andes; (c) the western slope of the Colombian Cordillera Oriental, Serranía de Perijá and Venezuelan Andes; (d) Colombian Cordillera Central and Cordillera Occidental; and (e) northern Peru, eastern Ecuador and south-eastern Colombia. Median values are shown as solid lines, and the $95 \%$ highest posterior densities (HPDs) as dashed lines. Bars are proportional to the number of genealogies with values in the specific time interval. Blue lines correspond to 1000 of the genealogies used to estimate the 95\% HPD of the population sizes. The median values of the parameter describing changes in population sizes are shown with the corresponding 95\% HPD range. All groups except those in panel (b) show signals of expansion, but such signals are significant only in panel (d).
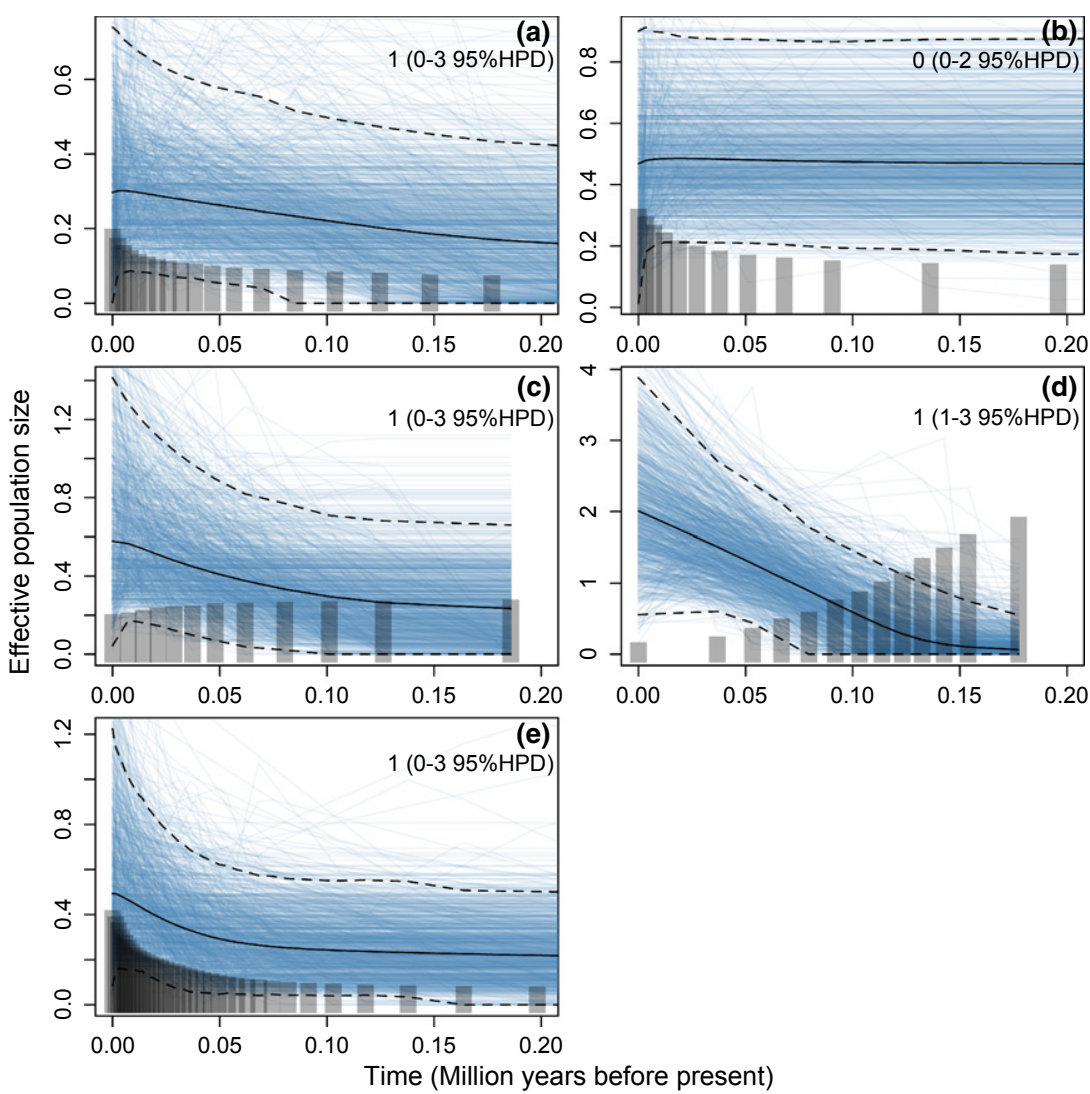

2009) as opposed to highly dispersive species from open environments (Cadena et al., 2011). In addition, P. brunnescens is a relatively old lineage compared with other Andean bird species (Fjeldså, 2012); its marked genetic structure may indicate that its populations have had more time to accumulate genetic differentiation than populations of species with more recent incumbency in the region.

\section{Effect of geographical barriers}

The distribution of genetically differentiated groups of $P$. brunnescens is associated with montane regions bounded by arid/lowland habitats and inter-Andean valleys known to shape genetic structure of other Neotropical montane birds (Weir, 2009). For example, the clade from Sierra Nevada de Santa Marta is bounded by the Cesar Depression and lowlands of northern Colombia. Geographical limits in Peru are more uncertain owing to sparse sampling, yet the Northern Andes clade could be limited in the south by the arid valley of the upper Huallaga River. Sampling areas extending north and south of the Huallaga in the Peruvian Central Andes could help our understanding of the historical effect of barriers in this region. The southern boundary of the central Peru clade is likely to be associated to one of the major dry valleys in the region (Mantaro, Apurímac, or Urubamba; GutiérrezPinto et al., 2012). However, overt geographical barriers do not fully account for differentiated populations. For example, the distribution of the clade from the Venezuelan northern mountains crosses the Turbio-Yaracuy Depression and ends in the Lara region of the Mérida Cordillera where no obvious geographical barrier occurs.

Two pairs of phylogroups within the Northern Andes occur on opposite slopes of mountain ranges: one in the Andes of southern Colombia and Ecuador, and the other in the Cordillera Oriental of Colombia. Although divergence on opposite mountain slopes separated by high elevations has received little attention in the literature (Parra et al., 2009), the differentiation across opposite slopes of Northern Andean ranges suggests that high-elevation areas have limited gene flow between slopes in the forest-dwelling P. brunnescens (see also Chaves et al., 2011). This is consistent with the expected role of high-elevation passes as physiological barriers to dispersal in tropical montane organisms (Janzen, 1967) and suggests that extreme conditions imposed by high-elevations habitats may restrict migration and promote opportunities for allopatric differentiation in species with narrow and conserved ecological niches (Cadena et al., 2012).

The phylogroups occupying different slopes of the Cordillera Oriental include samples from opposite slopes of the Venezuelan Andes, suggesting gene flow across the low-elevation Táchira depression. Likewise, samples of a population located south of the Marañon Valley are related to populations located north of this valley, suggesting some historical permeability to gene flow or recent population expansion (Isler et al., 2012). More generally, our data suggest genetic exchange to varying degrees across different valleys in the 
Northern Andes. For example, differentiation between populations separated by the Cauca Valley is apparently lacking, but it is considerable between populations isolated by the Magdalena Valley in Colombia, as shown in other studies (Cadena et al., 2007; Gutiérrez-Pinto et al., 2012; Isler et al., 2012). This pattern may be related to the closer geographical distance between populations separated by the Cauca Valley, or the higher elevations of this valley compared with those of the Magdalena (Cadena et al., 2007).

The phylogenetic break between southern Peru and Bolivia, where no obvious geographical or habitat discontinuity exists, has been described in other Andean birds (Cadena \& Cuervo, 2010; Chaves et al., 2011; Gutiérrez-Pinto et al., 2012; Isler et al., 2012). Range limits of young endemics and differentiated populations not attributable to geographical barriers in this region may have resulted from differentiation in climatically stable, refugial areas through the Pleistocene (Fjeldså et al., 1999; Gutiérrez-Pinto et al., 2012). The estimated divergence date associated with this phylogenetic break in our analysis is concordant with the hypothesis of divergence during the Pleistocene. Similar processes may account for phylogeographical breaks seemingly unrelated to geographical barriers at the southern end of the Colombian Cordillera Central and Cordillera Occidental, and along the eastern slope of the Colombian Cordillera Oriental.

The above patterns illustrate the complex array of opportunities for intraspecific diversification in the Neotropical mountains provided by their complex geography and environmental conditions (Graham et al., 2010). Additionally, the dynamic history of environmental conditions at putative physical and ecological barriers may have exerted important influences on evolutionary differentiation (Guarnizo et al., 2009).

\section{Timing of differentiation and demographic history}

The molecular-clock analyses and the extent and patterns of genetic differentiation seen among populations indicate that species- and population-level differentiation in Premnoplex occurred over a protracted period. The divergence of $P$. tate $i$ and $P$. brunnescens dates roughly to the late Miocene ( $c$. 7.6 Ma), supporting previous divergence dates estimated with few individuals (Pérez-Emán et al., 2010b). Intraspecific diversification in $P$. brunnescens is estimated to have occurred from the late Miocene to the Pliocene (from c. 3.2 to $5.3 \mathrm{Ma}$ ), coinciding with the timing of orogenic processes in the Andes, especially the major uplift during the last 10 million years (Gregory-Wodzicki, 2000; Mora et al., 2010). The relatively recent uplift of the Northern Andes resulted in an increase in montane forest area available for colonization and differentiation, and probably reduced gaps between older mountain ranges such as the Central Andes and the Venezuelan Andes (Hoorn et al., 2010). Divergence times estimated here suggest that the Northern Andean uplift could have linked different montane regions, allowing P. brunnescens and other montane taxa to acquire their current distributions. Potential associations between Andean uplift and evolutionary diversification have been documented in studies of birds and other organisms (Pérez-Emán, 2005; Cadena et al., 2007; Ribas et al., 2007; Särkinen et al., 2007; Koscinski et al., 2008; Guarnizo et al., 2009).

The divergence date between samples from South America and Central America (from 2.0 to 6.3 Ma) coincides with the closure of the Panamanian Isthmus dating to the late Miocene and Pliocene (Coates et al., 2004; but see Montes et al., 2012). This timing is consistent with the hypothesis that avifaunal interchange between continents, particularly of forest specialists, occurred in concert with the isthmus formation (Weir et al., 2009; Smith \& Klicka, 2010). Tectonic and volcanic activity during the same period resulted in the highlands of Costa Rica and Panama obtaining their present form (reviewed by Barrantes, 2009). This points to the importance of mountain uplift for the colonization of Central America.

A second burst of differentiation dating to the last million years resulted in the differentiation of populations from the Northern Andes and also in the split between populations from southern Peru and Bolivia; such events were probably related to climatic changes during the Quaternary. Furthermore, although credible intervals of population sizes were broad and only one of the four analyses suggested that demographic expansion was significant, estimated population sizes showed fluctuations since their most recent common ancestor. This pattern, together with the marked genetic structure, the concordance in some of the phylogenetic breaks with those existing in other species, and the occurrence of phylogeographical breaks seemingly unrelated to geographical barriers, appears to be most compatible with predictions of the dry refugia model of Pleistocene habitat dynamics (Ramírez-Barahona \& Eguiarte, 2013). However, our data do not obviously reject predictions of the moist forest model (Ramírez-Barahona \& Eguiarte, 2013); the downslope displacement of montane forest assumed by this model would result in corridors of favourable habitat across lowlands and inter-Andean valleys during glacial periods, which could account for patterns of population expansion. In any event, we see no evidence of alternating periods of population expansion and contraction associated with climatic change as documented in temperate-zone species (e.g. Shapiro et al., 2004).

The evidence of expansion over the last 200,000 years in the clade formed by populations from the Cordillera Central and Cordillera Occidental of Colombia, which bound the Cauca Valley, could be explained by both the dry refugia and moist forest models of vegetation dynamics. The estimated elevational range of lower montane forest in the Last Glacial Maximum in the Colombian Andes was 800-1400 m (Hooghiemstra \& van der Hammen, 2004), thus encompassing most of the elevational range in the Cauca Valley (Appendix S3). In addition, palynological evidence indicates that montane forest elements existed in this valley some 10,000 years 
ago (Berrío et al., 2002). Elevational displacement of forests may partly account for the demographic expansion pattern and the lack of genetic structure across this valley in P. brunnescens and other species (Cadena et al., 2007; GutiérrezPinto et al., 2012; Isler et al., 2012) if these cordilleras were connected by corridors of favourable habitat (moist forest model) or if both areas shared a refugium from which populations expanded to occupy their current ranges (dry refugia model).

In contrast to patterns discussed above, the population of the eastern slope of the Cordillera Oriental of Colombia and the Venezuelan Andes appears to have been demographically stable. This may reflect that some montane areas served as ecoclimatic refugia, where populations were relatively unaffected by Pleistocene glacial cycles. Taken together, our results showing different demographic patterns in different regions suggest that the overall effect of climatological phenomena on the distribution of habitats and thus the potential distribution and population size of our study species was probably not geographically uniform (see also d'Horta et al., 2011). Although similar results showing demographic changes over the Pleistocene have been documented in other organisms (Bisconti et al., 2011; Chaves et al., 2011; Batalha-Filho et al., 2012), future studies should aim to connect episodes of localized climatic and habitat change with patterns and processes of evolutionary differentiation.

\section{ACKNOWLEDGEMENTS}

This study was funded by the Facultad de Ciencias, Universidad de los Andes, Colombia (E.V. and C.D.C.), National Science Foundation (DEB-0910285 to R.T.B. and A.M.C., and DEB-0841729 to R.T.B.), Lewis and Clark Exploration Fund, Wilson Ornithological Society, American Ornithologists' Union, Society of Systematic Biologists, Chapman Fund of the American Museum of Natural History, Society of Integrative and Comparative Biology (to A.M.C.), and the Centro de Desarrollo Científico y Humanístico (CDCH) of the Universidad Central de Venezuela (to J.P.E.). We thank collectors and curators of the following institutions for tissue samples: The Field Museum, Marjorie Barrick Museum, Instituto Alexander von Humboldt, Instituto de Ciencias Naturales de la Universidad Nacional de Colombia, Colección Ornitológica Phelps, Instituto de Zoología y Ecología Tropical de la Universidad Central de Venezuela, Museo de Historia Natural ANDES, and Louisiana State University Museum of Natural Science. We thank G. Bravo, E. Derryberry, J. Miranda and L. Hernández for help with laboratory work; Y. López, K. Certuche, J. P. López, J. Miranda, M. Lentino, Y. Carreño, L. Hernández, C. Azpúrua and V. Gómez for field assistance; J.L. Parra, A.J. Crawford for comments on earlier versions of this manuscript; and members of Laboratorio de Biología Evolutiva de Vertebrados for their support. We thank the national authorities of Colombia and Venezuela for granting research permits.

\section{REFERENCES}

Antonelli, A., Nylander, J.A.A., Persson, C. \& Sanmartín, I. (2009) Tracing the impact of the Andean uplift on Neotropical plant evolution. Proceedings of the National Academy of Sciences USA, 106, 9749-9754.

Barrantes, G. (2009) The role of historical and local factors in determining species composition of the highland avifauna of Costa Rica and western Panama. Revista de Biología Tropical, 57, 333-349.

Batalha-Filho, H., Sebastian Cabanne, G. \& Miyaki, C.Y. (2012) Phylogeography of an Atlantic Forest passerine reveals demographic stability through the last glacial maximum. Molecular Phylogenetics and Evolution, 65, 892-902.

Berrío, J.C., Hooghiemstra, H., Marchant, R. \& Rangel, O. (2002) Late-glacial and Holocene history of the dry forest area in the south Colombian Cauca Valley. Journal of Quaternary Science, 17, 667-682.

Biomatters Development Team (2008) Geneious Pro. Version 4.5.5. Biomatters Ltd, Auckland. Available at: http://www. geneious.com/.

Bisconti, R., Canestrelli, D., Colangelo, P. \& Nascetti, G. (2011) Multiple lines of evidence for demographic and range expansion of a temperate species (Hyla sarda) during the last glaciation. Molecular Ecology, 20, 5313-5327.

Bouckaert, R.R. (2010) DensiTree: making sense of sets of phylogenetic trees. Bioinformatics, 26, 1372-1373.

Bowie, R.C.K., Fjeldså, J., Hackett, S.J., Bates, J.M. \& Crowe, T.M. (2006) Coalescent models reveal the relative roles of ancestral polymorphism, vicariance, and dispersal in shaping phylogeographical structure of an African montane forest robin. Molecular Phylogenetics and Evolution, 38, 171-188.

Burney, C.W. \& Brumfield, R.T. (2009) Ecology predicts levels of genetic differentiation in Neotropical birds. The American Naturalist, 174, 358-368.

Cadena, C.D. \& Cuervo, A.M. (2010) Molecules, ecology, morphology, and songs in concert: how many species is Arremon torquatus (Aves: Emberizidae)? Biological Journal of the Linnean Society, 99, 152-176.

Cadena, C.D., Klicka, J. \& Ricklefs, R.E. (2007) Evolutionary differentiation in the Neotropical montane region: molecular phylogenetics and phylogeography of Buarremon brush-finches (Aves, Emberizidae). Molecular Phylogenetics and Evolution, 44, 993-1016.

Cadena, C.D., Gutiérrez-Pinto, N., Dávila, N. \& Chesser, R.T. (2011) No population genetic structure in a widespread aquatic songbird from the Neotropics. Molecular Phylogenetics and Evolution, 58, 540-545.

Cadena, C.D., Kozak, K.H., Gómez, J.P., Parra, J.L., McCain, C.M., Bowie, R.C.K., Carnaval, A.C., Moritz, C., Rahbek, C., Roberts, T.E., Sanders, N.J., Schneider, C.J., VanDerWal, J., Zamudio, K.R. \& Graham, C.H. (2012) Latitude, elevational climatic zonation and speciation in New World vertebrates. Proceedings of the Royal Society B: Biological Sciences, 279, 194-201. 
Cárdenas, M.L., Gosling, W.D., Sherlock, S.C., Poole, I., Pennington, R.T. \& Mothes, P. (2011) The response of vegetation on the Andean flank in western Amazonia to Pleistocene climate change. Science, 331, 1055-1058.

Chapman, F.M. (1921) The distribution of bird life in the Urubamba Valley of Peru. Bulletin of the United States National Museum, 117, 1-138.

Chaves, J.A., Weir, J.T. \& Smith, T.B. (2011) Diversification in Adelomyia hummingbirds follows Andean uplift. Molecular Ecology, 20, 4564-4576.

Claramunt, S., Derryberry, E.P., Cadena, C.D., Cuervo, A.M., Sanín, C. \& Brumfield, R.T. (2013) Phylogeny and classification of Automolus foliage-gleaners and allies (Furnariidae). The Condor, 115, 375-385.

Coates, A.G., Collins, L.S., Aubry, M.P. \& Berggren, W.A. (2004) The geology of the Darién, Panama and the late Miocene-Pliocene collision of the Panama arc with northwestern South America. Geological Society of America Bulletin, 116, 1327-1344.

Colinvaux, P.A., De Oliveira, P.E. \& Bush, M.B. (2000) Amazonian and Neotropical plant communities on glacial time-scales: the failure of the aridity and refuge hypotheses. Quaternary Science Reviews, 19, 141-169.

Darriba, D., Taboada, G.L., Doallo, R. \& Posada, D. (2012) jModelTest 2: more models, new heuristics and parallel computing. Nature Methods, 9, 772-772.

Derryberry, E.P., Claramunt, S., Derryberry, G., Chesser, R.T., Cracraft, J., Aleixo, A., Pérez-Emán, J., Remsen, J.V. \& Brumfield, R.T. (2011) Lineage diversification and morphological evolution in a large-scale continental radiation: the Neotropical ovenbirds and woodcreepers (Aves: Furnariidae). Evolution, 65, 2973-2986.

Drummond, A.J. \& Rambaut, A. (2007) BEAST: Bayesian evolutionary analysis by sampling trees. BMC Evolutionary Biology, 7, 214.

Drummond, A.J., Suchard, M.A., Xie, D. \& Rambaut, A. (2012) Bayesian phylogenetics with BEAUti and the BEAST 1.7. Molecular Biology and Evolution, 29, 19691973.

Dupanloup, I., Schneider, S. \& Excoffier, L. (2002) A simulated annealing approach to define the genetic structure of populations. Molecular Ecology, 11, 2571-2581.

Edgar, R.C. (2004) MUSCLE: multiple sequence alignment with high accuracy and high throughput. Nucleic Acids Research, 32, 1792-1797.

Farris, J.S., Kallersjo, M., Kluge, A.G. \& Bult, C. (1995) Constructing a significance test for incongruence. Systematic Biology, 44, 570-572.

Fjeldså, J. (2012) Diversification of the Neotropical avifauna: disentangling the geographical patterns of persisting ancient taxa and phylogenetic expansions. Ornitología Neotropical, 23 (Supplement), 13-27.

Fjeldså, J., Lambin, E. \& Mertens, B. (1999) Correlation between endemism and local ecoclimatic stability documented by comparing Andean bird distributions and remotely sensed land surface data. Ecography, 22, 63-78.
García-Moreno, J. \& Fjeldså, J. (2000) Chronology and mode of speciation in the Andean avifauna. Isolated vertebrate communities in the tropics: Proceedings of the IV International Symposium, Zoologisches Forshungsinstitute und Museum A. Koenig, Bonn (ed. by G. Rheinwald), pp. 2546. Zoologisches Forschungsinstitut und Museum Alexander Koenig, Bonn.

García-Moreno, J., Arctander, P. \& Fjeldså, J. (1999) A case of rapid diversification in the Neotropics: phylogenetic relationships among Cranioleuca spinetails (Aves, Furnariidae). Molecular Phylogenetics and Evolution, 12, 273-281.

Gentry, A.H. (1982) Neotropical floristic diversity: phytogeographical connections between Central and South America, Pleistocene climatic fluctuations, or an accident of the Andean orogeny? Annals of the Missouri Botanical Garden, 69, 557-593.

Graham, C.H., Silva, N. \& Velasquez-Tibatá, J. (2010) Evaluating the potential causes of range limits of birds of the Colombian Andes. Journal of Biogeography, 37, 1863-1875.

Greeney, H.F. (2008) The spotted barbtail (Premnoplex brunnescens): a review of taxonomy, distribution, and breeding biology, with additional observations from northeastern Ecuador. Boletín de la Sociedad Antioqueña de Ornitología, 18, $1-9$.

Gregory-Wodzicki, K.M. (2000) Uplift history of the central and northern Andes: a review. Geological Society of America Bulletin, 112, 1091-1105.

Guarnizo, C.E., Amezquita, A. \& Bermingham, E. (2009) The relative roles of vicariance versus elevational gradients in the genetic differentiation of the high Andean tree frog, Dendropsophus labialis. Molecular Phylogenetics and Evolution, 50, 84-92.

Gutiérrez-Pinto, N., Cuervo, A.M., Miranda, J., Pérez-Eman, J.L., Brumfield, R.T. \& Cadena, C.D. (2012) Non-monophyly and deep genetic differentiation across low-elevation barriers in a Neotropical montane bird (Basileuterus tristriatus; Aves: Parulidae). Molecular Phylogenetics and Evolution, 64, 156-165.

Heled, J. (2010) Extended Bayesian skyline plot tutorial. Available at: http://beast-mcmc.googlecode.com/svn-history/ r3936/trunk/doc/tutorial/EBSP/ebsp-tut.pdf.

Heled, J. \& Drummond, A.J. (2008) Bayesian inference of population size history from multiple loci. BMC Evolutionary Biology, 8, 289.

Heled, J. \& Drummond, A.J. (2010) Bayesian inference of species trees from multilocus data. Molecular Biology and Evolution, 27, 570-580.

Hewitt, G. (2000) The genetic legacy of the Quaternary ice ages. Nature, 405, 907-13.

Hooghiemstra, H. \& van der Hammen, T. (2004) Quaternary ice-age dynamics in the Colombian Andes: developing an understanding of our legacy. Philosophical Transactions of the Royal Society B: Biological Sciences, 359, 173-180.

Hoorn, C., Wesselingh, F.P., ter Steege, H., Bermudez, M.A., Mora, A., Sevink, J., Sanmartín, I., Sanchez-Meseguer, A., Anderson, C.L., Figueiredo, J.P., Jaramillo, C., Riff, D., 
Negri, F.R., Hooghiemstra, H., Lundberg, J., Stadler, T., Särkinen, T. \& Antonelli, A. (2010) Amazonia through time: Andean uplift, climate change, landscape evolution, and biodiversity. Science, 330, 927-931.

d'Horta, F.M., Cabanne, G.S., Meyer, D. \& Miyaki, C.Y. (2011) The genetic effects of Late Quaternary climatic changes over a tropical latitudinal gradient: diversification of an Atlantic Forest passerine. Molecular Ecology, 20, 1923-1935.

Isler, M.L., Cuervo, A.M., Bravo, G.A. \& Brumfield, R.T. (2012) An integrative approach to species-level systematics reveals the depth of diversification in an Andean thamnophilid, the Long-tailed Antbird. The Condor, 114, 571-583.

Jansson, R. \& Dynesius, M. (2002) The fate of clades in a world of recurrent climatic change: Milankovitch oscillations and evolution. Annual Review of Ecology and Systematics, 33, 741-777.

Janzen, D.H. (1967) Why mountain passes are higher in the tropics. The American Naturalist, 101, 233-249.

Koscinski, D., Handford, P., Tubaro, P.L., Sharp, S. \& Lougheed, S.C. (2008) Pleistocene climatic cycling and diversification of the Andean treefrog, Hypsiboas andinus. Molecular Ecology, 17, 2012-2025.

Lartillot, N. \& Philippe, H. (2006) Computing Bayes factors using thermodynamic integration. Systematic Biology, 55, 195-207.

Librado, P. \& Rozas, J. (2009) DnaSP v5: a software for comprehensive analysis of DNA polymorphism data. Bioinformatics, 25, 1451-1452.

Marin, J.C., González, B.A., Poulin, E., Casey, C.S. \& Johnson, W.E. (2013) The influence of the arid Andean high plateau on the phylogeography and population genetics of guanaco (Lama guanicoe) in South America. Molecular Ecology, 22, 463-482.

Mata, H., Fontana, C.S., Maurício, G.N., Bornschein, M.R., de Vasconcelos, M.F. \& Bonatto, S.L. (2009) Molecular phylogeny and biogeography of the eastern tapaculos (Aves: Rhinocryptidae: Scytalopus, Eleoscytalopus): cryptic diversification in Brazilian Atlantic Forest. Molecular Phylogenetics and Evolution, 53, 450-462.

McGuire, J.A., Witt, C.C., Altshuler, D.L. \& Remsen, J.V., Jr (2007) Phylogenetic systematics and biogeography of hummingbirds: Bayesian and maximum likelihood analyses of partitioned data and selection of an appropriate partitioning strategy. Systematic Biology, 56, 837-856.

Miller, M.A., Pfeiffer, W. \& Schwartz, T. (2010) Creating the CIPRES science gateway for inference of large phylogenetic trees. Proceedings of the Gateway Computing Environments Workshop (GCE), pp. 1-8. Association for Computing Machinery, New Orleans, LA.

Montes, C., Bayona, G., Cardona, A., Buchs, D.M., Silva, C.A., Moron, S., Hoyos, N., Ramírez, D.A., Jaramillo, C.A. \& Valencia, V. (2012) Arc-continent collision and orocline formation: closing of the Central American seaway. Journal of Geophysical Research: Solid Earth, 117, 1-25.
Moore, W.S. (1995) Inferring phylogenies from mtDNA variation: mitochondrial-gene trees versus nuclear-gene trees. Evolution, 49, 9.

Moore, R.P., Robinson, W.D., Lovette, I.J. \& Robinson, T.R. (2008) Experimental evidence for extreme dispersal limitation in tropical forest birds. Ecology Letters, 11, 960-968.

Mora, A., Baby, P., Roddaz, M., Parra, M., Brusset, S., Hermoza, W. \& Espurt, N. (2010) Tectonic history of the Andes and sub-Andean zones: implications for the development of the Amazon drainage basin. Amazonia, landscape and species evolution: a look into the past (ed. by C. Hoorn and F.P. Wesselingh), pp. 38-60. Blackwell Publishing, Chichester, UK.

Paradis, E. (2010) Pegas: an R package for population genetics with an integrated-modular approach. Bioinformatics, 26, 419-420.

Parker, T.A., Schulenberg, T.S., Graves, G.R. \& Braun, M.J. (1985) The avifauna of the Huancabamba region, northern Peru. Ornithological Monographs, 36, 169-197.

Parra, J.L., Remsen, J.V., Jr, Alvarez-Rebolledo, M. \& McGuire, J.A. (2009) Molecular phylogenetics of the hummingbird genus Coeligena. Molecular Phylogenetics and Evolution, 53, 425-434.

Pérez-Emán, J.L. (2005) Molecular phylogenetics and biogeography of the Neotropical redstarts (Myioborus; Aves, Parulinae). Molecular Phylogenetics and Evolution, 37, 511528.

Pérez-Emán, J.L., Mumme, R.L. \& Jabłoński, P.G. (2010a) Phylogeography and adaptive plumage evolution in Central American subspecies of the Slate-throated Redstart (Myoborus miniatus). Ornithological Monographs, 67, 90102.

Pérez-Emán, J.L., Hernández, L.L. \& Brumfield, R.T. (2010b) Phylogenetic relationships of the white-throated barbtail, Premnoplex tatei (Furnariidae), an endemic of the northeastern mountain range of Venezuela. The Condor, 112, 561-570.

Picard, D., Sempere, T. \& Plantard, O. (2007) A northward colonisation of the Andes by the potato cyst nematode during geological times suggests multiple host-shifts from wild to cultivated potatoes. Molecular Phylogenetics and Evolution, 42, 308-316.

de Queiroz, K. (2007) Species concepts and species delimitation. Systematic Biology, 56, 879-886.

Quintero, E., Ribas, C.C. \& Cracraft, J. (2013) The Andean Hapalopsittaca parrots (Psittacidae, Aves): an example of montane-tropical lowland vicariance. Zoologica Scripta, 42, 28-43.

R Development Core Team (2012) R: a language and environment for statistical computing. Version 2.14.2. R Foundation for Statistical Computing, Vienna. Available at: http://www.r-project.org/.

Rambaut, A. \& Drummond, A.J. (2007) Tracer v1.5. Available at: http://beast.bio.ed.ac.uk/software/tracer/.

Ramírez-Barahona, S. \& Eguiarte, L.E. (2013) The role of glacial cycles in promoting genetic diversity in the 
Neotropics: the case of cloud forests during the last glacial maximum. Ecology and Evolution, 3, 725-738.

Remsen, J.V. (2003) Furnariidae (ovenbirds). Handbook of the birds of the world. Vol. 8: Broadbills to tapaculos (ed. by J. del Hoyo, A. Elliott and D. Christie), pp. 162-357. Lynx Editions, Barcelona.

Ribas, C.C., Moyle, R.G., Miyaki, C.Y. \& Cracraft, J. (2007) The assembly of montane biotas: linking Andean tectonics and climatic oscillations to independent regimes of diversification in Pionus parrots. Proceedings of the Royal Society B: Biological Sciences, 274, 2399-408.

Ronquist, F., Teslenko, M., van der Mark, P., Ayres, D.L., Darling, A., Hohna, S., Larget, B., Liu, L., Suchard, M.A. \& Huelsenbeck, J.P. (2012) MrBayes 3.2: efficient Bayesian phylogenetic inference and model choice across a large model space. Systematic Biology, 61, 539-542.

Sanín, C., Cadena, C.D., Maley, J.M., Lijtmaer, D.A., Tubaro, P.L. \& Chesser, R.T. (2009) Paraphyly of Cinclodes fuscus (Aves: Passeriformes: Furnariidae): implications for taxonomy and biogeography. Molecular Phylogenetics and Evolution, 53, 547-555.

Särkinen, T.E., Newman, M.F., Maas, P.J.M., Maas, H., Poulsen, A.D., Harris, D.J., Richardson, J.E., Clark, A., Hollingsworth, M. \& Pennington, R.T. (2007) Recent oceanic long-distance dispersal and divergence in the amphi-Atlantic rain forest genus Renealmia L.f. (Zingiberaceae). Molecular Phylogenetics and Evolution, 44, 968-980.

Shapiro, B., Drummond, A.J., Rambaut, A. et al. (2004) Rise and fall of the Beringian steppe bison. Science, 306, 15611565.

Shepard, D.B. \& Burbrink, F.T. (2009) Phylogeographic and demographic effects of Pleistocene climatic fluctuations in a montane salamander, Plethodon fourchensis. Molecular Ecology, 18, 2243-2262.

Smith, B.T. \& Klicka, J. (2010) The profound influence of the late Pliocene Panamanian uplift on the exchange, diversification, and distribution of New World birds. Ecography, 33, 333-342.

Sukumaran, J. \& Holder, M.T. (2010) DendroPy: a Python library for phylogenetic computing. Bioinformatics, 26, 1569-1571.

Swofford, D.L. (1998) PAUP*: phylogenetic analysis using parsimony ( ${ }^{*}$ and other methods). Sinauer Associates, Sunderland, MA.

Tamura, K., Peterson, D., Peterson, N., Stecher, G., Nei, M. \& Kumar, S. (2011) MEGA5: molecular evolutionary genetics analysis using maximum likelihood, evolutionary distance, and maximum parsimony methods. Molecular Biology and Evolution, 28, 2731-2739.

Templeton, A.R., Crandall, K.A. \& Sing, C.F. (1992) A cladistic-analysis of phenotypic associations with haplotypes inferred from restriction endonuclease mapping and DNAsequence data. 3. Cladogram estimation. Genetics, 132, 619-633.
Vuilleumier, F. (1969) Pleistocene speciation in birds living in the high Andes. Nature, 223, 1179-1180.

Weir, J.T. (2006) Divergent timing and patterns of species accumulation in lowland and highland neotropical birds. Evolution, 60, 842-855.

Weir, J.T. (2009) Implications of genetic differentiation in Neotropical montane forest birds. Annals of the Missouri Botanical Garden, 96, 410-433.

Weir, J.T. \& Price, M. (2011) Andean uplift promotes lowland speciation through vicariance and dispersal in Dendrocincla woodcreepers. Molecular Ecology, 20, 45504563.

Weir, J.T., Bermingham, E. \& Schluter, D. (2009) The Great American Biotic Interchange in birds. Proceedings of the National Academy of Sciences USA, 106, 21737-21742.

Zwickl, D.J. (2006) Genetic algorithm approaches for the phylogenetic analysis of large biological sequence datasets under the maximum likelihood criterion. PhD Thesis, The University of Texas, Austin, TX.

\section{SUPPORTING INFORMATION}

Additional Supporting Information may be found in the online version of this article:

Appendix S1 Information on the samples included in the study, including identification number in the figures (ID), taxon, locality, geographical coordinates, museum catalogue number and GenBank accession numbers.

Appendix S2 Additional tables, including primers used, partitioning schemes considered for phylogenetic analyses, and uncorrected $p$-distances within and among major clades and within and among Northern Andes phylogroups.

Appendix S3 Additional figures, including phylogenetic trees, plots and maps.

\section{BIOSKETCH}

Eugenio Valderrama is a Colombian biologist interested in evolutionary diversification and historical biogeography of birds and plants. He is currently a PhD student at the Royal Botanic Garden Edinburgh and the University of Edinburgh. This study was part of his undergraduate and master's theses in biological sciences completed in the Departamento de Ciencias Biológicas, Universidad de los Andes in Bogotá, Colombia, where he was supervised by C.D.C. in the Laboratorio de Biología Evolutiva de Vertebrados.

Author contributions: all authors conceived the study; E.V., A.M.C. and J.L.P. collected the data; E.V. performed analyses; E.V. and C.D.C. wrote the manuscript; all authors contributed to and approved the final version of the manuscript.

Editor: Michael Patten 